\title{
Characterisation of Biochar Obtained from Organic Material and Its Application for Removal of Ciprofloxacin
}

\author{
SIJA ARUN' ${ }^{1}$ and PAYAL MAHARATHI ${ }^{*}$ \\ Department of Civil Engineering, SRM Institute of Science and Technology, Chennai, India. \\ ${ }^{*}$ Corresponding author E-mail: sijaarun08@gmail.com, niki.maharathi1 @ gmail.com
}

http://dx.doi.org/10.13005/ojc/350323

(Received: April 12, 2019; Accepted: May 13, 2019)

\begin{abstract}
Ciprofloxacin is the second generation of quinolone antibiotic used to treat infections in living beings. After using this antibiotic, some percentages of the compound are not metabolized in the body and is excreted along with the urine and excreta. This will reach the treatment plant and the conventional treatment methods are not designed to treat these micropollutants, so it is released into the environment. The presence of ciprofloxacin is detected in surface water samples collected from different areas of the world. This study is conducted to find an effective adsorbent that can remove the ciprofloxacin from wastewater. Biochar produced from agricultural waste can be used as an effective adsorbent. Biochar is prepared under a process called pyrolysis which is carried out under relatively higher temperatures and low oxygen content. In this study, biochar is prepared from rice husk at different temperatures ie, $200^{\circ} \mathrm{C}, 250^{\circ} \mathrm{C}$ and $300^{\circ} \mathrm{C}$. The adsorption experiments were conducted at the varying contact time, varying the initial concentration of biochar and varying residence time in the muffle furnace. The biochar prepared at $300^{\circ} \mathrm{C}$ showed $96 \%$ removal in a contact time of 90 minutes. FTIR results showed that stretching vibration of $-\mathrm{OH}$ group, phenolic $\mathrm{C}-\mathrm{OH}$ stretch, $\mathrm{C}-\mathrm{O}$ in phenol, $\mathrm{C}-\mathrm{H}$ stretching vibration and $\mathrm{C}=\mathrm{O}$ stretching play a vital role in ciprofloxacin adsorption. The pseudo-second-order kinetic reaction and Freundlich isotherm agreed well with ciprofloxacin adsorption process. SEM images after adsorption showed a drastic change in the surface morphology of the rice husk biochar.
\end{abstract}

Keywords: Adsorption, Biochar, Ciprofloxacin

\section{INTRODUCTION}

Antibiotics are widely used in the treatment and prevention of infections. They may either kill or prevent the growth of bacteria. Ground and surface water get contaminated by pharmaceutical products which are an environmental problem causing widespread concern. Pharmaceutical products are discharged from private houses, hospitals, industries that reach municipal sewage treatment plants. These pharmaceutical products present in wastewater are not treated specifically in treatment plant, so they are not completely removed from wastewater and are directly allowed to discharge in to the environment.

The primary direction of the movement of the pharmaceuticals products into the environment is through human excretion and animal feeding

This is an Open Access article licensed under a Creative Commons license: Attribution 4.0 International (CC- BY). Published by Oriental Scientific Publishing Company @ 2018

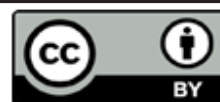


operations. The industrial compounds are still present in wastewater after passing the wastewater treatment and enter through point discharge and surface runoff. Pharmaceutical compounds are the trace organic compounds present in the environment. The presence of trace organic compounds is having dangerous effects on wildlife and aquatic life. The antibiotics are present in drinking water sources that need to be examined. As microorganisms play an important role in wastewater treatment by biological processes for decomposing organic materials present in the wastewater, the trace pharmaceutical compounds present in the wastewater may cause death of microorganisms, hence it has to be removed. Ciprofloxacin is an antibiotic compound that is used for various health issues like headaches, nervousness, nausea, vomiting etc. Ciprofloxacin is the second generation of fluoroquinolone antibiotic. The presence of ciprofloxacin is not only contaminating the water sources but also increasing the risk to life. Ciprofloxacin is a common antibiotic prescribed by various medical practitioners for treatment of infections and those infections which are caused due to Gram-negative bacteria. But it targets both Gram-positive and Gram-negative bacteria. The main source of entry of ciprofloxacin in to the environment is incomplete metabolism by the body ${ }^{10}$. Other sources are pharmaceutical industry effluent and surface runoff from landfill sites. Because of high solubility in water, occurrence of ciprofloxacin is reported in soil, surface water and wastewater all over the world ${ }^{11}$. The amount of ciprofloxacin present in various sources of water is increasing as the demand of the antibiotic is increasing by the population which is produced by the pharmaceutical industry.

Biochar produced from agricultural waste which is highly rich in carbon is made from the process called pyrolysis and pyrolysis of biomass process is carried out under lower temperatures. Biochar is used as a good adsorbent because of its large specific surface area, porous nature, the presence of functional groups and mineral components. It removes various environmental pollutants present in soil and water. For enhancing soil mostly agricultural waste is converted into fertilizer which increase the fertility of the soil. The amount of solid waste generated from various sources can be reduced by utilizing the waste in the preparation of the biochar which can be helpful for the environment as it reduces the amount of waste deposited in the landfills and can be helpful to make the climate change less severe. Biochar is used to remove antibiotic compounds, Poly Aromatic Hydrocarbons, naphthalene and heavy metals ${ }^{1}$. Biochar is economical and it is not having any adverse effects on the environment. The pyrolysis process is dependent on temperature and can be optimized in order to produce biochar or energy. Pyrolysis process depends on the pyrolytic temperature residence time, adsorbent size, and rate of heating.

The materials that are required for the preparation of biochar are easily available. Biochar as compared to other adsorbent material is a low-cost adsorbent. Adsorption capacities are more in biochar as compared to other adsorbents. The biochar can be prepared from any kind of waste organic material. Thus, the waste material can be converted into a useful product which reduces the load on the landfill.

The emerging contaminants can be removed from the wastewater by adsorption process which is considered as one of the green technologies. The adsorption process shows high removal efficiency with minimum waste generation. A large number of research works have been carried out across the globe to find a suitable adsorbent material which has maximum adsorption, less cost and less waste generation ${ }^{1}$. The tea leaves were used for the preparation of biochar for the removal of ciprofloxacin as millions of tons of used tea leaves were wasted after use that causes a burden on the ecological environment. The used tea leaves were pyrolyzed at $450^{\circ} \mathrm{C}$ has an excellent absorption ability and $33 \%$ removal efficiency for ciprofloxacin ${ }^{2}$.

The cassava dregs were used for the preparation of biochar at three different temperature and the biochar prepared at higher temperatures had the more surface area and larger micropore volumes i.e. at $750^{\circ} \mathrm{C}$. The biochar produced at $750^{\circ} \mathrm{C}$ had the highest sorption affinity of ciprofloxacin ${ }^{3}$. Adsorption of fluroquinolone antibiotics and biochar prepared from sludge is a low-cost absorbent material for controlling the pollution caused by fluroquinolone antibiotics ${ }^{4}$. The ciprofloxacin removal from artificial wastewater with sawdust, was also studied earlier. The supernatant was analysed at a different wavelength and the removal efficiency is maximum at $277 \mathrm{~nm}^{5}$. 
The biochar prepared from municipal sludge is a low-cost adsorbent material for controlling the pollution caused by fluroquinolone antibiotics. The removal efficiency by using sludge derived biochar is nearly about $76 \%{ }^{4}$. The biochar that was produced through the microwave pyrolysis was used for removal of silver from an aqueous solution. Biochar prepared from bio-solids is a promising method to minimize water contamination and biosolids can be effectively managed by this environmentally sustainable approach to re-use it in the future ${ }^{6}$. The removal of ciprofloxacin using the biochar prepared from peels of grapefruit was also showed good results. Biochar prepared with chitosan which is another adsorbent used for ciprofloxacin removal. The efficiency of chitosan biochar hydrogen beads for ciprofloxacin removal is $35 \%$ and chitosan biochar hydrogen beads is an adsorbent which has proved to be an economical and sustainable adsorbent material ${ }^{8}$.

This study was conducted to find the effectiveness biochar to remove ciprofloxacin antibiotic from wastewater. The biochar was produced from the pyrolysis of rice husk which is a locally available waste material. The aim of the investigation was to identify an economical absorbent for removing of ciprofloxacin from wastewater.

\section{Methodology Materials}

Ciprofloxacin was purchased from Sigma Aldrich. 100 ppm solution was prepared by dissolving it in $4 \% \mathrm{NaOH}$ solution. Rice husk was collected from rice mill, Chennai. Milli $Q$ water was used in experimental procedure.

\section{Biochar Preparation}

The rice husk was collected and shredded into small pieces and then washed with acetone. The moisture content, ash content and volatile matter content of rice husk was measured by using ASTM methods. The required amount of rice husk was measured with the help of weighing machine. The pieces of material dried was taken in a crucible having tight fitted lid. The biochar was prepared at different pyrolytic temperature in a muffle furnace with certain duration of time. After attaining the particular temperature, it was allowed to cool down and then removed from the furnace. To determine the effect of residence time, the biochar was removed from the muffle furnace at different times. The biochar was then stored in desiccators so that outside moisture doesn't affect it. The biochar was prepared at four different temperatures that are $200^{\circ} \mathrm{C}, 250^{\circ} \mathrm{C}, 300^{\circ} \mathrm{C}$ and $350^{\circ} \mathrm{C}$. But the biochar prepared at $350^{\circ} \mathrm{C}$ turned into ash. The biochar was then powdered and sieved to get uniform size for the adsorption experiments.

\section{Adsorption Procedure}

The stock solution was prepared by dissolving ciprofloxacin in $4 \% \mathrm{NaOH}$ buffer solution and then $100 \mathrm{ppm}$ standard solution was prepared from it.100 ppm ciprofloxacin solution was used for all adsorption experiments.

- $\quad 100 \mathrm{ppm}$ of standard solution was spiked over $0.2 \mathrm{~g}$ of biochar to find the effect of shaking time on removal. The experiment was done for three different biochar prepared at $200^{\circ} \mathrm{C}, 250^{\circ} \mathrm{C}$ and $300^{\circ} \mathrm{C}$. Four sets of the conical flask were placed in the shaker at $80 \mathrm{rpm}$ for different shaking time i.e. $45 \mathrm{~min}, 60 \mathrm{~min}, 90 \mathrm{~min}$ and 120 minute.

- $100 \mathrm{ppm}$ of standard solution was spiked over different concentration of biochar to find the effect of concentration of biochar on removal. The experiment was done for three different biochar prepared at $200^{\circ} \mathrm{C}, 250^{\circ} \mathrm{C}$ and $300^{\circ} \mathrm{C}$ with a constant shaking time.

- $100 \mathrm{ppm}$ of standard solution was spiked over 0.2 $\mathrm{g}$ of biochar produced at $250^{\circ} \mathrm{C}, 200^{\circ} \mathrm{C}, 300^{\circ} \mathrm{C}$ in five different flasks to find the effect of residence time of biochar in the muffle furnace.

- To find the effect of initial concentration of ciprofloxacin, 20ppm, 40ppm, 60ppm, 80ppm and $100 \mathrm{ppm}$ solutions were spiked with optimum concentration of biochar and was shaken for optimum time.

\section{Characterisation of biochar}

Biochar yield was found out by weighing the rice husk before and after biochar preparation. The SEM (FEl Quanta 200 F, Thermo Fisher scientific) images used to study the morphology of the biochar before and after adsorption. Presence of functional groups before and after adsorption were studied by using FTIR (IRT racer - 100, Shimadzu, Japan). The specific surface area and pore size were determined by BET (Smart sorb93, Smart instruments company, India) analysis.

\section{Ciprofloxacin Analysis}

After each experiment, the solution was 
placed in the micro-centrifuge tubes. All the tubes were centrifuged at 5000rpm for 15 min which allowed the biochar to settle that was present in each of the sample. Then the samples were filtered and tested in UV-Vis Spectro-photometer at 285 $\mathrm{nm}$. Removal efficiency was calculated by using the following equation

$\left(C_{0}-C_{e}\right) \times 100 / C_{0}$

Where $\mathrm{C}_{\mathrm{e}}$ and $\mathrm{C}_{0}$ are final and initial concentration of ciprofloxacin respectively. Amount of adsorption was calculated by using the equation $\left(\mathrm{C}_{0}-\mathrm{C}_{\mathrm{e}}\right) \times \mathrm{v} / \mathrm{w}$, where $\mathrm{w}$ is the weight of the adsorbent used $v$ is the sample volume.

\section{Adsorption kinetics and isotherms}

From the kinetic experiments it was found that biochar prepared at $300^{\circ} \mathrm{C}$ was showing best results. So, sorption kinetics of $300^{\circ} \mathrm{C}$ biochar was analysed with pseudo first order and pseudo second order model.

Freundlich and Langmuir isotherm models were used analyse the best fit for the sorption experiments.

\section{RESULTS AND DISCUSSIONS}

Biochar preparation and adsorption experiments were carried out as per the procedure explained in the methodology. The biochar prepared at different pyrolytic temperature ie, $200^{\circ} \mathrm{C}, 250^{\circ} \mathrm{C}$, $300^{\circ} \mathrm{C}$ were used for the experiments with variation in time, variation with concentration of biochar, variation with residence time in the muffle furnace and variation with initial concentration of the sorbent. The organic material was kept inside the muffle furnace for certain duration of time which is an important factor for the preparation of biochar. Biochar cannot be produced at a higher pyrolytic temperature from the organic material. The temperature should be always less than $700^{\circ} \mathrm{C}$ for preparing biochar, depending on the characteristics of the material. The pyrolytic temperature always varies for the conversion of the biomass into biochar. For rice husk the maximum temperature was found to be $300^{\circ} \mathrm{C}$, above this temperature the rice husk became ash. The efficiency of the adsorption of biochar is also affected by the pyrolytic temperature making it a significant factor in adsorption process. The capacity of adsorption increases as the surface area increases, which in turn depends on the temperature; with the increase in temperature, there is an increase in surface area. This depends on the type of feedstock material that is being used for the preparation of biochar.

\section{Characterisation of rice husk}

The moisture content, ash content and volatile matter content of rice husk is shown in Table 1. The biochar yield of the rice husk biochar was found to be $78.5 \%$.

\section{Table 1: Characteristics of rice husk}

\begin{tabular}{lccc}
\hline Feed stock & $\begin{array}{c}\text { Moisture } \\
\text { content(\%) }\end{array}$ & $\begin{array}{c}\text { Ash } \\
\text { content (\%) }\end{array}$ & $\begin{array}{c}\text { Volatile matter } \\
\text { content (\%) }\end{array}$ \\
\hline Rice husk & 11.2 & 14.7 & 79.8 \\
\hline
\end{tabular}

\section{Effect of removal efficiency with time}

The adsorption efficiency of the rice husk was determined by using a UV Spectrophotometer. Ciprofloxacin adsorption experiment was carried out using the rice husk biochar that was prepared at $200^{\circ} \mathrm{C}$, $250^{\circ} \mathrm{C}$, and $300^{\circ} \mathrm{C}$ was shaken for different time i.e. 45 min, $60 \mathrm{~min}, 90 \mathrm{~min}$ and $120 \mathrm{~min}$ in orbital shaker.

The Fig. 1 shows the the removal efficiency of ciprofloxacin with time.The removal efficiency increases with the temperature at which the biochar is prepared. The biochar that was produced at $200^{\circ} \mathrm{C}$ showed removal efficiency of ciprofloxacin which is around $50 \%$ at $48 \mathrm{~min}$ then it is decreasing with the increase of time. The biochar that was produced at $250^{\circ} \mathrm{C}$ showed a removal efficiency of around $85 \%$ at $90 \mathrm{~min}$ and then it reaches equilibrium. The biochar that was produced at $300^{\circ} \mathrm{C}$ gave the removal efficiency of $96 \%$ at 90 min and became stable at 120 minutes. Hence the optimum time of removal is considred as 90 minutes. The biochar produced at $300^{\circ} \mathrm{C}$ is the best biochar which gave the highest removal efficiency.

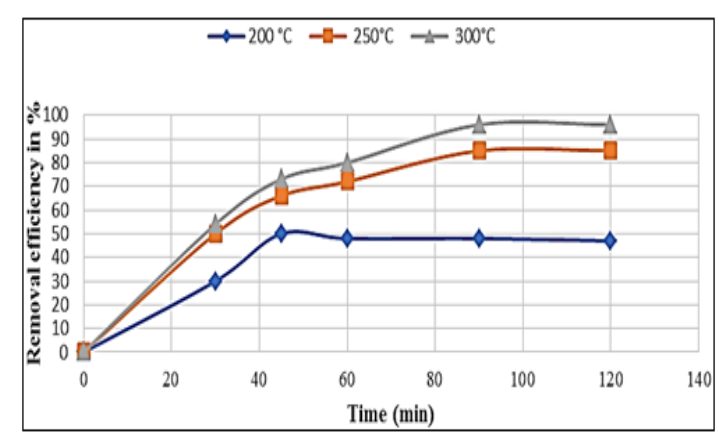

Fig. 1. Removal efficiency v/s shaking time 


\section{Effect of different concentration of biochar}

As shown in Fig. 2, ciprofloxacin adsorption on rice husk biochar was minimum at $0.2 \mathrm{~g}$. Removal efficiency decreased with the decrease of the concentration of the biochar. The biochar produced from three different temperatures that are at $200^{\circ} \mathrm{C}$, $250^{\circ} \mathrm{C}$ and $300^{\circ} \mathrm{C}$ gave a maximum removal efficiency of $52 \%, 75 \%$ and $82 \%$ respectively. Since the optimum time obtained from the previous experiment is $90 \mathrm{~min}$ all the flasks were shaken for a constant shaking time ie, 90 minutes. The biochar prepared at $300^{\circ} \mathrm{C}$ is showing the maximum removal efficiency and the optimum biochar concentration is 0.6 gram.

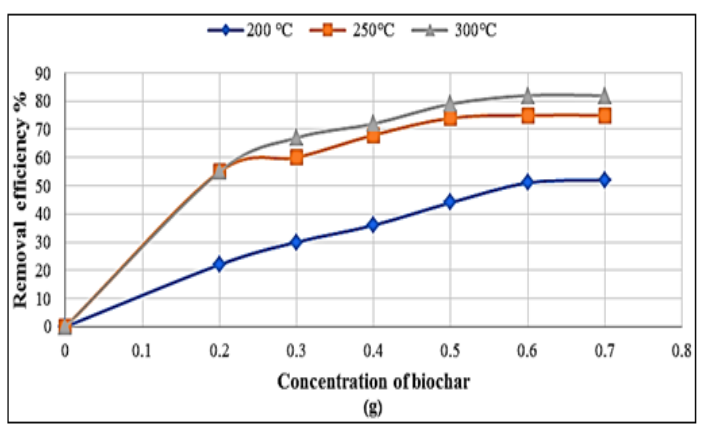

Fig. 2. Removal efficiency v/s concentration of biochar

Effect of different pyrolytic temperature with different residence time inside the muffle furnace

The residence time of biochar preparation also play an important role in the removal ciprofloxacin from the aqueous solution. Fig. 3 shows the relation between removal and residence time. For all the three type of biochars the ciprofloxacin adsorption were maximum at 120 minutes. It indicates that the optimum residence time for biochar preparation is 120 minutes. The maximum removal efficiency of biochar produced at $200^{\circ} \mathrm{C}, 250^{\circ} \mathrm{C}$ and $300^{\circ} \mathrm{C}$ are $68 \%, 80 \%$, and $82 \%$ respectively.

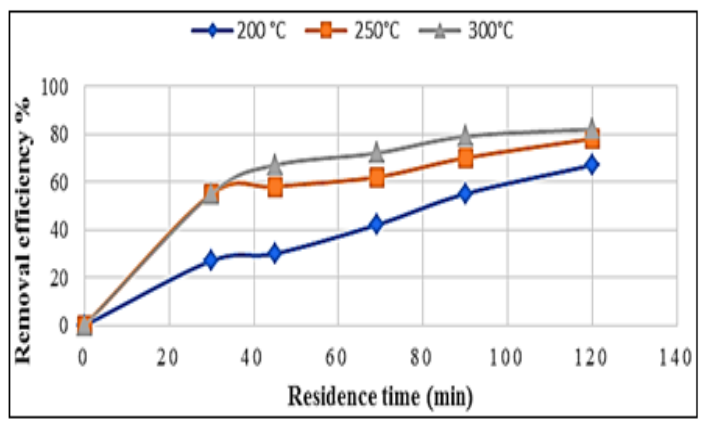

Fig. 3. Removal efficiency v/s residence time

The optimum time and concentration of biochar for this experiment are $90 \mathrm{~min}$ and $0.6 \mathrm{~g}$ which was obtained from the previous experiments. This experiment also shows that biochar at $300^{\circ} \mathrm{C}$ is the best biochar for removing ciprofloxacin from aqueous solution.

\section{Effect of different initial concentration of ciprofloxacin solution}

The experiment was done with 20ppm, 40ppm, 60ppm 80ppm and 100ppm of ciprofloxacin solutions. The removal efficiency versus initial concentration of ciprofloxacin are shown in Fig. 4. For this experiments the optimum time was 90 min and optimum biochar concentration was $0.6 \mathrm{~g}$. Since the maximum removal efficiency of ciprofloxacin was obtained for biochar prepared at $300^{\circ} \mathrm{C}$ in the previous experiments, that biochar is only considered for this experiments. As the concentration of ciprofloxacin increases, the removal efficiency also increases. The results were also used to find the best fit in isotherm models.

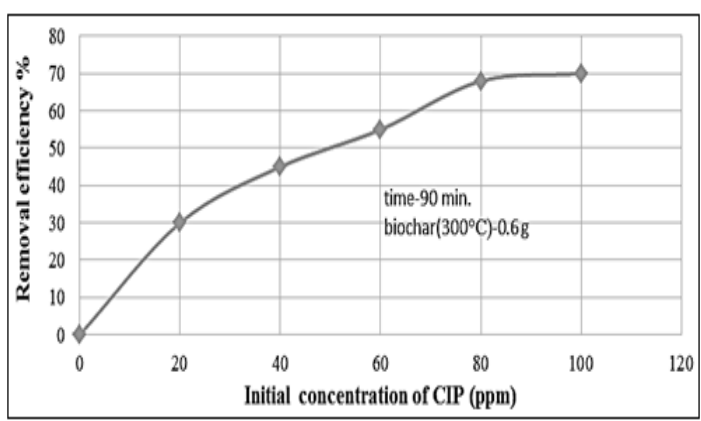

Fig. 4. Removal efficiency v/s concentration of ciprofloxacin

\section{Characterisation Results}

The maximum removal efficiency of the ciprofloxacin is at $300^{\circ} \mathrm{C}$ at $90 \mathrm{~min}$ of shaking, so further analysis was carried out using the adsorption of ciprofloxacin with the above-mentioned temperature of biochar shaken with the sample. The characteristic functional group of rice husk biochar was identified by analysing the FT-IR spectra. The FT-IR spectra were inspected from 400 to $4000 \mathrm{~cm}^{-1}$ infrared spectral region of the rice husk biochar before and after adsorption are shown in Fig. 5. There are a greater number of peaks in infrared spectra of the rice husk biochar before adsorption. According to the graph, there is a broad peak around $3400 \mathrm{~cm}^{-1}$, which shows the $-\mathrm{OH}$ functional groups including the stretching vibrations. The peaks at $2950 \mathrm{~cm}^{-1}$ and $2850 \mathrm{~cm}^{-1}$, shows symmetric and asymmetric stretching vibrations of Methylene ${ }^{2}, \mathrm{~A}$ small peak between $2500 \mathrm{~cm}^{-1}$ and $2000 \mathrm{~cm}^{-1}$ shows 
the presence of triple bonds. At $1600 \mathrm{~cm}^{-1}$ the $\mathrm{C}=\mathrm{C}$ bond in the aromatic ring, at $1500 \mathrm{~cm}^{-1}$ the $\mathrm{C}-\mathrm{H}$ alkanes and at $1050 \mathrm{~cm}^{-1} \mathrm{C}-\mathrm{O}$ in phenol are clearly identified ${ }^{12}$. When compared to the infrared spectra after adsorption result, some of the peaks are formed and some peaks are disappeared from the spectra. The new peaks are at $3400 \mathrm{~cm}^{-1}, 1620 \mathrm{~cm}^{-1}$ and $1050 \mathrm{~cm}^{-1}$ and they are assigned to amino acids, hydroxyl group, stretching vibrations of amide group, phenolic $\mathrm{C}-\mathrm{H}$ stretching vibrations, $\mathrm{C}=\mathrm{O}$ stretching respectively. The sharp peak $1050 \mathrm{~cm}^{-1}$ was reduced in FTIR image after adsorption which indicates there is a considerable reduction in $\mathrm{C}-\mathrm{O}$ in phenol group. The peaks get flattened between $2500 \mathrm{~cm}^{-1}$ and $2000 \mathrm{~cm}^{-1}$ indicates the role of triple bond compounds in adsorption. In general, stretching vibration of $-\mathrm{OH}$ group, phenolic $\mathrm{C}-\mathrm{OH}$ stretch, $\mathrm{C}-\mathrm{O}$ in phenol, $\mathrm{C}-\mathrm{H}$ stretching vibration and $\mathrm{C}=\mathrm{O}$ stretching play a vital role in ciprofloxacin adsorption.

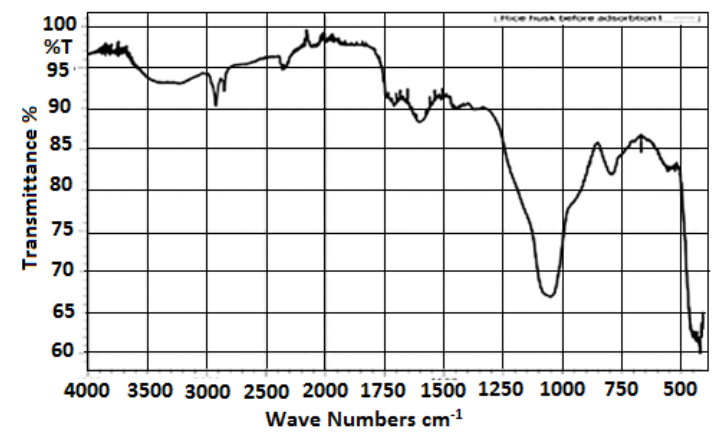

(a)

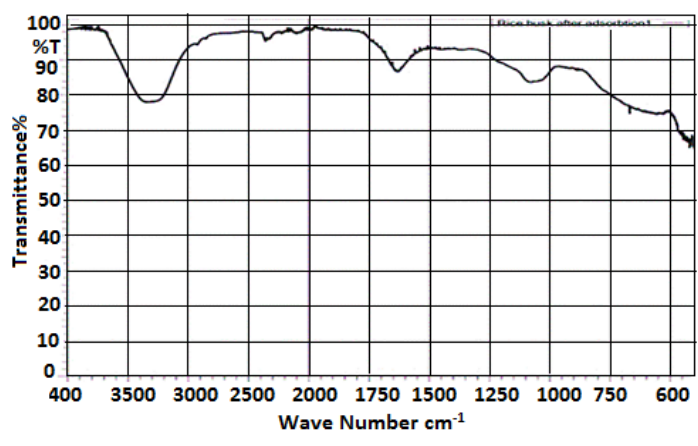

(b)

Fig. 5. FT-IR Result before and after adsorption

From BET analysis, the average pore diameter, the pore capacity and surface area of the biochar after adsorption were $4.76 \mathrm{~nm}, 0.018 \mathrm{~cm} 3 / \mathrm{g}$ and $9.6 \mathrm{~m}^{2} / \mathrm{g}$. This is almost same as that tealeaves biochar $^{2}$ which also gives a removal efficiency around $80 \%$.
Figure 6 shows the SEM images of biochar before adsorption experiment and after adsorption experiment. The morphology of the biochar before and after adsorption was different. Some few tiny pores are seen on the surface of the biochar after adsorption as compared to the surface of the biochar prior to adsorption. As shown in Fig 6(a) there are non-uniform pores. For rice husk after ciprofloxacin adsorption a number of rod-shaped particles appeared which shows active points of adsorption.

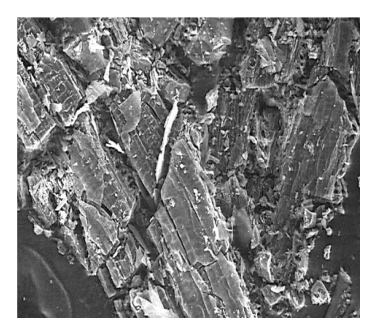

(a)

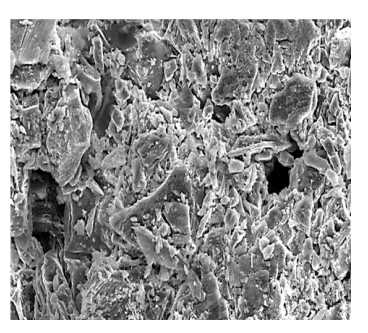

(b)
Fig. 6. SEM images of rice husk biochar (a) before (b) after adsorption

\section{Adsorption kinetics}

The kinetic studies conducted were correlated with two models, one is pseudo first order reaction model and the other one is pseudo second order reaction model. The pseudo first order model is shown in Fig. 7. Since the biochar prepared at 300 $\mathrm{OC}$ is showing best results, kinetic studies were done only for this biochar.

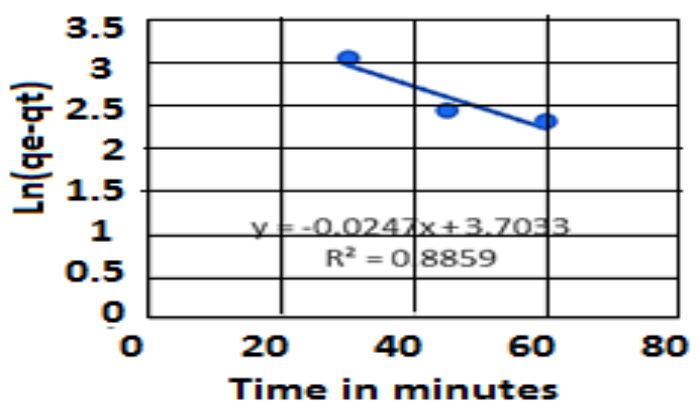

Fig. 7. Pseudo first order reaction for $3000 \mathrm{C}$ biochar

The equation for pseudo first order reaction is given below.

$\ln \left(q_{e}-q_{t}\right)=\ln q_{e}-k_{1} t$

the equation for pseudo second order reaction is given below

$\frac{1}{\mathrm{q}}=\frac{1}{\mathrm{k}^{2} \mathrm{q} e^{2} \mathrm{t}}+\frac{1}{\mathrm{q} e}$ 
Where $q_{t}$ is the ciprofloxacin adsorbed at time $t$ and qe is the amount ciprofloxacin adsorbed at equilibrium. $\mathrm{k}_{1}$ and $\mathrm{k}_{2}$ are constants. The pseudo second order reaction model is shown in Figure 8.

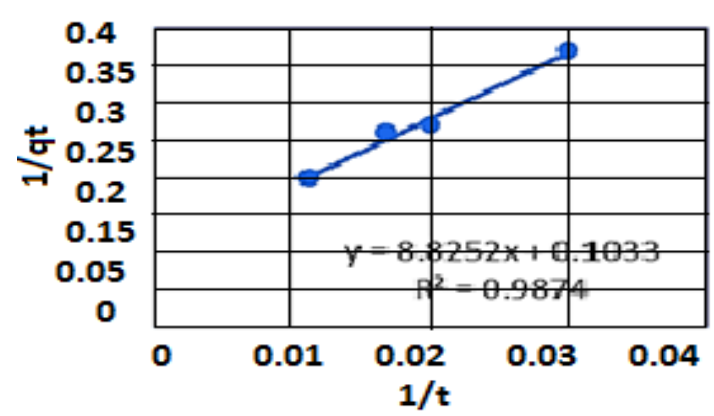

Fig. 8. Pseudo second order reaction for $300^{\circ} \mathrm{C}$ biochar

From both the graphs it is clear that the best fit obtained is for pseudo second order reaction, because the $R^{2}$ value obtained is 0.9874 for this model.

\section{Adsorption isotherm}

For the following isotherm experiments, different concentration of biochar was considered. The experiment was conducted for $200^{\circ} \mathrm{C}, 250^{\circ} \mathrm{C}$, and $300^{\circ} \mathrm{C}$ biochar's. The Langmuir model and the Freundlich model are the commonly used isotherm models to explain the nature of adsorption and adsorption capacity.

The Langmuir and Freundlich equations are shown below.

$\frac{1}{\mathrm{Q}_{\mathrm{e}}}=\frac{1}{\mathrm{Q}^{\mathrm{O}}}+\frac{1}{\mathrm{KQ}^{\circ} \mathrm{Ce}}$

$Q_{e}=K_{f} \mathrm{Ce}^{1 / n}$

Where $Q_{e}$ is the amount of CIP adsorbed per unit mass of adsorbent.

$\mathrm{C}_{\mathrm{e}}$ is the CIP concentration in the solution at equilibrium,

$\mathrm{K}_{\mathrm{f}}$ is the Freundlich coefficient,

$\mathrm{n}$ is the Freundlich constant,

$\mathrm{K}$ is the surface adsorption affinity constant, $Q_{0}$ is he adsorption capacity.

The Langmuir and Freundlich isotherms of the biochar prepared at $300^{\circ} \mathrm{C}$ are shown in Fig. 9 and Figure 10.

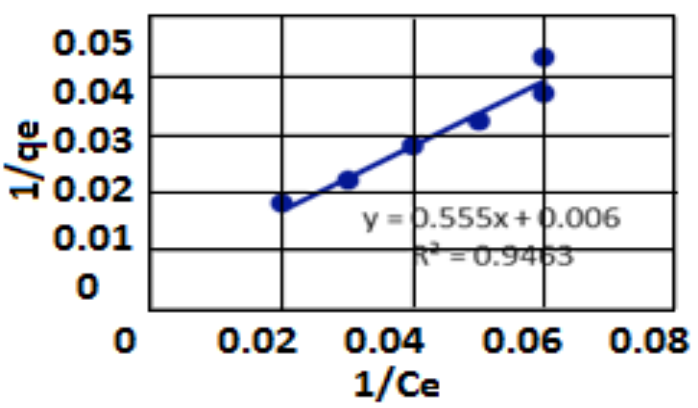

Fig. 9. Langmuir model for 300 OC biochar

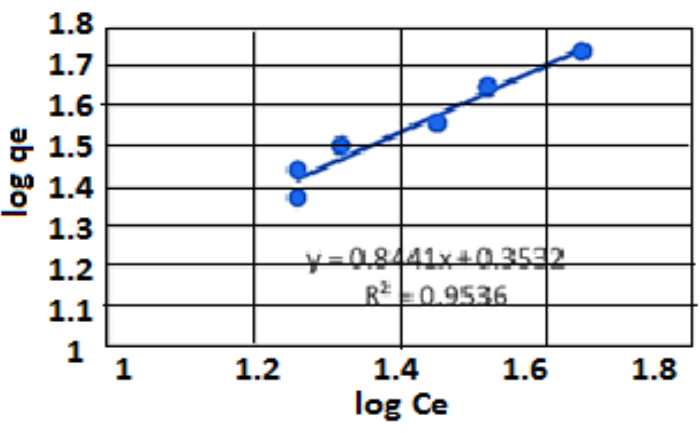

Fig. 10. Freundlich model for 300 0C biochar

According to above two models Freundlich isotherm is the best fit for explaining the adsorption capacity. The $R^{2}$ value for this one is 0.9536 . Fangze Li et al., (2016) also explains the Freundlich isotherm is the best fit for adsorbing ciprofloxacin on biochar prepared from cassava drugs. $1 / \mathrm{n}$ value close to 1 indicates that isotherm is linear.

\section{CONCLUSION}

This experiment was conducted with an aim to find a cost-effective way to remove ciprofloxacin antibiotic that is contaminating the various water sources, since the water treatment plant and wastewater treatment plant is not treating the ciprofloxacin antibiotic specifically. The rice husk was used for the preparation of biochar and further experiment was done using this biochar for adsorption of ciprofloxacin antibiotic. The adsorption experiments reveal that rice husk biochar is very effective in removing the ciprofloxacin from the solution. The removal efficiency was found to be $96 \%$ at 90 min using the biochar produced at $300^{\circ} \mathrm{C}$. Thus a waste material can be converted into a useful adsorbent with low cost. 


\section{ACKNOWLEDGEMENT}

The author acknowledge the support given by SRM research institute kattankulathur,
Chennai.

\section{Confilicts of Interest}

The authors declare no confilict of interest.

\section{REFERENCES}

1. Daughton C.G Daughton and T.A. Ternes.; Pharmaceutical and Personal care Products in the Environment: Agents of subtle change, Environmental Health Perspectives., 1999, 107, 907-938.

2. R.C. Yang, X, Flowers, H.S. Yang, X, Flowers, singer, P.C.; Occurrence and removal of pharmaceuticals and personal care products (PPCPs) in an advanced wastewater reclamation plant. Water Res., 2011, 45, 5218-5228.

3. A Carmalin Sophia, Limab Eder C.;Removal of emerging contaminants from the environment by adsorption. Ecotoxicology and Environmental Safety., 2018, 150, 1-17.

4. Li Jie, Yu Guangwei , Pan Lanjia, Li Chunxing, You Futian, XieShengyu, WangYie, Ma Jianli, Shang Xiaofu.; Study of ciprofloxacin removal by biochar obtained from used tea leaves, JES-01400., 2018

5. Li Fangze, Feng Dan, Deng Hui, Yu Huamei, Ge Chengjun.;Effects of biochars prepared from cassava dregs on sorption behaviour of ciprofloxacin. Procedia Environmental Sciences., 2016, 31, $795-803$.

6. Yao Hong, Lu Jian, Wu Jun, Lu Zeyu, Wilson P. Chris, Shen Yan.; Adsorption of Fluoroquinolone Antibiotics by Wastewater Sludge Biochar: Role of the Sludge Source. Water Air Soil Pollut., 2013, 224, 1370.

7. Bajpai Sunil Kumar, Bajpai Manjula, and Rai Neelam.;Sorptive removal of ciprofloxacin hydrochloride from simulated wastewater using sawdust: Kinetic study and effect of $\mathrm{pH}$ ISSN 0378-4738., 2016.

8. Elsa Antunes, Mohan V. Jacob, Graham Brodie, Philip A. Schneider.;Silver removal from aqueous solution by biochar produced from bio-solids via microwave pyrolysis. Journal of Environmental Management., 2017, 203, 264e272.

9. Afzal Muhammad Zaheer ,Sun Xue-Fei, Liu Jun, Song Chao, Wang Shu-Guang, Javed Asif.;Enhancement of ciprofloxacin sorption on chitosan/biochar hydrogel beads. Science of the Total Environment., 2018, 639, 560-569.

10. Y Sun Y., H Li, C Li.G.,Y Gao.B., Y Yue.Q., B Li.X.;Characterisation and ciprofloxacin adsorption properties of activated carbon prepared from biomass waste by $\mathrm{H}$ 3PO 4 activation, Bioresource technology., 2016, 217, 239-244.

11. Fagbohungbe Michael O., Herbert Ben M.J., Hurst Lois , Ibeto Cynthia N., Li Hong, Usmani Shams Q., Semple Kirk T.; The challenges of anaerobic digestion and the role of biochar in optimizing anaerobic digestion. Waste Management., 2016.

12. Li Ronghua, Deng Hongxia , Zhang Xiaofeng, Wang Jim J., Kumar Mukesh Awasthi, Wang Quan, Xiao Ran, Zhou Baoyue, Du Juan, Zhang Zengqiang.; High-efficiency removal of $\mathrm{Pb}$ (II) and humate by $\mathrm{a} \mathrm{CeO}_{2}-\mathrm{MoS}_{2}$ hybrid magnetic biochar. S0960-8524., 2018, 31, 485-8. 